\title{
ANALISIS SISTEM DAN PROSEDUR PENERIMAAN KAS PENDAPATAN ASLI DAERAH (PAD) PADA BADAN PENGELOLA PAJAK DAN RETRIBUSI DAERAH KOTA MANADO
}

\author{
Juanda Jeniver Polii ${ }^{1}$, Inggriani Elim ${ }^{2}$, Rudy Pusung ${ }^{3}$ \\ ${ }^{1,2,3}$ Jurusan Akuntansi, Fakultas Ekonomi dan Bisnis, Universitas Sam Ratulangi, J1. Kampus Bahu, Manado \\ 95115, Indonesia \\ Email : Juandajeniver@gmail.com
}

\begin{abstract}
Reform is a step taken by the government, one of which is in the area of local government financial management funds. Demands for the creation of good governance that has become the will of most people in achieving the goals and ideals of the nation and state. Accountability philosophically arises because of the power in the form of mandates / mandates given to someone to carry out their duties in order to achieve a certain goal by using existing supporting facilities. This study aims to analyze whether the system and procedures for implementing PAD receipts in the Regional Tax and Retribution Management Board of Manado City are adequate. The method of analysis used in this study is descriptive method. The results of this study indicate that the system and procedures for cash receipts carried out by the Regional Tax and Retribution Management Board of the City of Manado are in accordance with the systems and procedures contained in PERMENDAGRI 59 of 2007 for cash receipts, especially in regional taxes and levies

Keywords : Systems and Procedures, Cash Receipts, Local Revenue, Tax Management and Retribution Board of the City of Manado, PAD.
\end{abstract}

\section{PENDAHULUAN}

Reformasi ialah tahapan yang di laksanakan oleh pemerintah, salah satunya pada bidang pemerintah daerah pengelolaan keuangan. Tuntutan agar terciptanya pemerintahan yang baik yang menjadi kehendak masyarakat untuk mencapai cita-cita bangsa dan Negara. Adapun penerapan dripada otonomi daerah merupakan sebuah pemikiran baru untuk sistem penyelenggaraan, ketatanegaraan Indonesia memberi dukungan bagi jalannya pemerintah khususnya di daerah. Otonomi daerah adalah bagian dari demokratisasi untuk menciptakan sebuah sistem yang powershare pada setiap level pemerintah serta menuntut kemandirian sistem di daerah.

\section{TINJAUAN PUSTAKA}

Sistem Informasi Akuntansi. Bodnar dan Hopwood (2006:3) menyatakan bahwa Sistem informasi akuntansi adalah kumpulan sumber daya, yang dirancang untuk mengubah data keuangan dan data lainnya kedalam informasi. Informasi tersebut dikomunikasikan kepada pembuat keputusan.

Konsep Akuntansi. Harahap (2011:5) menyatakan bahwa akuntansi adalah menyangkut angka-angka yang dijadikan dasar untuk mengambil keputusan yang menggambarkan catatan dari transaksi perusahaan. Pontoh (2013:2) menjelaskan bahwa akuntansi pada dasarnya akan menghasilkan informasi dari sebuah sistem akuntansi yang ada dalam organisasi bisnis yang disebut dengan informasi akuntansi yang akan dimanfaatkan oleh pengguna seperti masyarakat umum, masyarakat intelektual (mahasiswa atau peneliti) dan para pengambil keputusan bisnis dalam organisasi. 
Akuntansi Pemerintahan. Bachtiar dkk (2002:3) menjelaskan bahwa akuntansi pemerintahan adalah suatu aktifitas pemberian jasa menyediakan informasi keuangan pemerintah berdasarkan proses pencatatan, pengklaifikasian transaksi keuangan pemerintah.

Konsep Sistem Pengendalian Intern. Dikutip dalam Robert (2013:44) Pengendalian Intern menurut COSO adalah rangkaian tindakan yang mencakup keseluruhan proses dalam organisasi.

Konsep Pendapatan Asli Daerah. Menurut Darise (2009:48) PAD ialah pendapatan yang diperoleh daerah lewat pemungutan berdasarkan perda sesuai dengan peraturan perundangundangan.

Sistem dan Prosedur Penerimaan Kas. Romney dan Steinbart (2006:2) sistem merupakan serangkaian dari komponen-komponen yang berhubungan, yang berinteraksi dalam mencapai tujuan.

Penelitian Terdahulu. Sunanto (2017) Analisis Efisiensi Dan Efektivitas Penerimaan Pendapatan Asli Daerah Terhadap Anggaran Pendapatan Dan Belanja Daerah (APBD) di Kabupaten Musi Banyuasin. Hasil pembahasan menunjukkan kinerja APBD DPPKAD Kabupaten Musi Banyuasin atas penerimaan PAD sudah efisien, tapi ditinjau dari sudut efektivitaskinerja APBD tidak efektif, karena realisasi yang diperoleh tidak bisa melebihi anggaran yang ditentukan. Karamoy (2013) Evaluasi Pelaksanaan Sistem dan Prosedur Penerimaan Kas di Dinas Pendapatan Kota Manado. Dispenda Kota Manado sudah menerapkan sistem dan prosedur penerimaan kas sesuai ketentuan pada peraturan tersebut. Aronan (2016) Evaluasi Penerapan Sistem Pengendalian Penerimaan Kas (Studi Kasus Pada Dinas Pendapatan Kota Manado). Hasil penelitian menunjukkan, untuk mewujudkan pengelolaan keuangan Negara yang akuntabel dan transparan, Dispenda Kota Manado melaksanakan sistem pengendalian penerimaan kas untuk mengontrol jalan pelaporan penerimaan kas dan kegiatan lainnya. Amelia (2017) Evaluasi Pelaksanaan Sistem dan Prosedur Penerimaan Kas (Studi Pada DPPKAD Kabupaten Gresik). Sistem dan prosedur penerimaan kas pada DPPKAD Kabupaten Gresik telah dilaksanakan dengan baik dan sesuai dengan peraturan yang berlaku. Karundeng (2015) Analisis Prosedur Penerimaan Pendapatan Daerah Melalui Bendahara Penerimaan Pada Dinas Pendapatan Pengelolaan Keuangan dan Aset Daerah (DPPKAD) Kabupaten Kepulauan Sitaro. Hasil penelitian diperoleh bahwa DPPKAD Kabupaten Kepulauan Sitaro telah menerapkan sistem dan prosedur penerimaan pendapatan daerah melalui bendahara penerimaan sesuai dengan PERMENDAGRI No.59 Tahun 2007.

\section{METODE PENELITIAN}

Jenis Penelitian. Jenis penelitian yang dipakai ialah jenis penelitian deskriptif kualitatif yang bermaksud untuk menyelidiki kondisi atau hal lain di BP2RD Kota Manado mengenai Sistem dan Prosedur Penerimaan Kas Pendapatan Asli Daerah (PAD) yang hasilnya dapat dipaparkan dalam bentuk laporan penelitian.

Tempat dan Waktu Penelitian. Penelitian ini dilakukan di Badan Pengelola Pajak dan Retribusi Daerah Kota Manado. Waktu penelitian dari bulan Agustus sampai dengan bulan Oktober 2018.

Jenis Data, Sumber Data dan Metode Pengumpulan Data. Jenis data yang digunakan yaitu data kualitatif. Sumber data yang digunakan ialah sumber primer dan sekunder. Data primer diambil langsung pada BP2RD Kota Manado. Sedangkan data sekunder yang dipakai dalam penelitian ini ialah data dari lembaga pengumpul data.

Metode dan Proses Analisis. Metode analisis data yang dipakai yaitu metode analisis deskriptif, yang dilakukan dengan cara mengidentifikasi sistem pencatatan yang menyangkut komponen sistem dan prosedur penerima PAD. Kemudian ditentukan kelebihan/kekurangan dari sistem tersebut dibandingkan dengan konsep teori tentang sistem informasi akuntansi 
menyangkut sistem pencatatan, kemudian ditarik kesimpulan efektif tidaknya sistem dan prosedur penerimaan PAD pada BP2RD Kota Manado.

\section{HASIL ANALISIS DAN PEMBAHASAN}

\subsection{Hasil Analisis}

Sistem dan Prosedur Penerimaan Kas, Badan Pengelola Pajak dan Retribusi Daerah berwenang melaksanakan Otonomi Daerah Kota untuk melaksanakan tugas desentralisasi, yaitu dalam tugas penerimaan kas: memungut dan/atau menerima pendapatan daerah wajib melakukan pemungutan dan/atau penerimaan sesuai peraturan perundangundangan. Prosedur sistem penerimaan kas:

1. Fungsi pihak terkait: PPK-SKPD, Pengguna Anggaran, Bendahara Penerimaan dan BUD (Bank).

2. Dokumen: STS, SSP, SSR, SKRD, TBP, Bukti Transfer, Nota Kredit Bank.

3. Catatan: Buku Jurnal Penerimaan Kas, Buku Besar dan Buku Besar Pembantu.

4. Prosedur: Pengguna Anggaran memberikan SKR yang sudah diterbitkan kepada Bendahara Penerimaan dalam melaksanakan verifikasi penerimaan pendapatan. Wajib Pajak/Wajib Retribusi memberikan uang. Bendahara Penerimaan melaksanakan verifikasi penerimaan uang dengan SKP/SKR yang bersangkutan. Setelah verifikasi, Bendahara Penerimaan mengeluarkan STBP dan Bendahara menyiapkan STS. Bendahara Penerimaan menyetor kepada bank disertai STS. STS yang telah diotorisasi diterima kembali oleh Bendahara Penerimaan untuk bukti pembukuan.

\section{Sistem dan Prosedur Pajak dan Retribusi}

1. Prosedur Penerimaan Pajak Daerah : (a) Pendaftaran WP Daerah; (b) Penetapan; dan (c) Penyetoran.

2. Prosedur Penerimaan Retribusi Daerah: (a) Pendaftaran WR Daerah; (b) Penetapan; dan (c) Penyetoran.

\subsection{Pembahasan}

Analisis Komponen-Komponen Sistem Pengendalian Intern. Menurut Robert (2013:44), komponen penting dalam sistem pengendalian intern Menurut COSO adalah sebagai berikut.

Pengendalian Lingkungan. Pelaksanaan sistem dan prosedur penerimaan kas yang dilakukan BP2RD Kota Manado mulai dari pencatatan, penggolongan dan transaksi keuangan secara manual ataupun terkomputerisasi sudah dilakukan dengan baik. Dalam pencatatan dan penggolongan, STS yang telah di otorisasi oleh bank dikembalikan kepada bendahara penerimaan untuk kemudian menjadi bukti pembukuan yang dicatat.

Aktivitas Pengendalian. Setiap dokumen dasar penerimaan kas harus diotorisasi dahulu oleh pejabat yang bersangkutan. Pada BP2RD Kota Manado, setiap bukti dasar penerimaan kas diotorisasi oleh pejabat berwenang. Dalam penerimaan kas pada pajak/retribusi dimulai dengan pengesahan bukti setoran pajak pada dinas, sebelum penerimaan tersebut disetor ke bank melalui STS.

Informasi dan Komunikasi. Pelaksanaan pengendalian intern terhadap formulir, dokumen dan catatan penerimaan kas hampir dilaksanakan dengan baik.

Pemantauan. Pemantauan dalam proses pelaksanaan penerimaan kas pada BP2RD Kota Manado telah dilaksanakan dengan baik. Dimana semua fungsi terkait tidak ada yang merangkap dua fungsi sekaligus. Semuanya dipisahkan secara independent sesuai dengan tugas yang akan dikerjakan.

Analisis Pelaksanaan Sistem dan Prosedur Penerimaan Kas. Dalam menjalankan sistem penerimaan kas yang berasal dari Pajak dan Retribusi Daerah pada BP2RD membagi tugas dan tanggungjawab kedalam beberapa fungsi Pengguna Anggaran, PPK-SKPD melalui Bendahara Penerimaan, Bank, Bidang Pembukuan. Wajib pajak/retribusi uang (setoran 
pajak/retribusi). Bendahara penerimaan kemudian verifikasi penerimaan uang SKP/SKR daerah. Setelah melakukan verifikasi, Bendahara Penerimaan mengeluarkan Surat Tanda Bukti Pembayaran (STBP). Kemudian Bendahara Penerimaan menyiapkan Surat Tanda Setor (STS). Setelah itu Bendahara penerimaan uang akan menyetor uang ke bank yang ditunjuk pemerintah (Bank SULUT) beserta STS.

Tabel 1. Perbandingan antara Permendagri dengan Sistem dan Prosedur Penerimaan Kas PAD Di Badan Pengelola Pajak dan Retribusi Daerah Kota Manado

\begin{tabular}{|c|c|c|c|}
\hline No & Permendagri 59 Tahun 2007 Pasal 89 & Hasil Penelitian & Keterangan \\
\hline 1 & Pihak/ Fungsi Terkait & $\begin{array}{l}\text { Pembagian tugas/fungsi } \\
\text { untuk penyimpan dan } \\
\text { pencatat yaitu fungsi } \\
\text { penyimpanan oleh PPK- } \\
\text { SKPD, PA, Bendahara } \\
\text { Penerimaan dan Bagian } \\
\text { pembukuan/akuntansi. }\end{array}$ & Sesuai \\
\hline 2 & Aktivitas & $\begin{array}{l}\text { Pelaksanaan aktivitas } \\
\text { terdapat prosedur untuk } \\
\text { menyetor bukti kas } \\
\text { masuk (SKP/SKR, TBP, } \\
\text { STS dan Nota Kredit } \\
\text { bank) dilakukan dimulai } \\
\text { PA, WP /WR, Bendahara } \\
\text { Penerimaan dan } \\
\text { selanjutnya uang disetor } \\
\text { ke bank. }\end{array}$ & Sesuai \\
\hline 3 & Dokumen & $\begin{array}{l}\text { Terdapat dokumen } \\
\text { penyetoran: } \\
\text { Ketetapan Pajak Daerah } \\
\text { (SKPD), Surat Ketetapan } \\
\text { Retribusi } \\
\text { (SKRD), Surat Daerah } \\
\text { Setor, Nota Kredit Bank. }\end{array}$ & Sesuai \\
\hline
\end{tabular}

Sumber: Data Olahan (2018)

Tabel 1 menjelaskan sistem dan prosedur penerimaan kas yang dilakukan BP2RD Kota Manado sesuai dengan PERMENDAGRI 59 Tahun 2007 mengenai penerimaan kas pajak maupun retribusi daerah.

\section{KESIMPULAN DAN SARAN}

\subsection{Kesimpulan}

Kesimpulan yang di ambil dari penelitian ini:

1. Pelaksanaan penerimaan pajak dan retribusi daerah pada BP2RD Kota Manado telah sesuai dengan PERMENDAGRI 59 Tahun 2007 meliputi fungsi yang terkait, dokumen yang dipakai.

2. STS ialah dokumen dasar yang dipakai untuk mencatat penerimaan kas dalam melaksanakan sistem dan prosedur penerimaan kas.

3. Pelaksanaan sistem dan prosedur penerimaan kas dipisahkan oleh beberapa fungsi yaitu, pada BP2RD berfungsi menyetor penerimaan kas, Bank berfungsi untuk menyimpan uang daerah. 


\subsection{Saran}

Saran diberikan:

1. BP2RD Kota Manado harus memperhatikan fungsi untuk mengimplementasikan prosedur pembukuan khususnya dalam penjurnalan.

2. Mengadakan bimbingan dan sosialisasi.

\section{DAFTAR PUSTAKA}

Amelia, I. R (2017) Evaluasi Pelaksanaan Sistem dan Prosedur Penerimaan Kas (Studi Pada DPPKAD Kabupaten Gresik). Jurnal Ilmu dan Riset Akuntansi.

Aronan, V. M, Tinangon, J dan Budiarso, S (2016) Evaluasi Penerapan Sistem Pengendalian Penerimaan Kas (Studi Kasus Pada Dinas Pendapatan Kota Manado). Jurnal EMBA.

Bachtiar. A Dkk (2002). Akuntansi Pemerintah. Erlangga : Jakarta

Bodnar. G, dan Hoopwood. W. (2004). Sistem informasi akuntansi edisi 9. Penerbit Andi. Yogyakarta

Darise. K (2009). Akuntansi Sektor Publik. Jilid 3. Penerbit Andi. Yogyakarta

Harahap. R (2011). Pengantar Akuntansi. Edisi Ke 2. Penerbit Andi. Yogyakarta

Karamoy (2013). Evaluasi Pelaksanaan Sistem dan Prosedur Penerimaan Kas Pada Dinas Pendapatan Kota Manado. Jurnal EMBA.

Karundeng, C. N, Ilat, V dan Runtu, T (2015) Analisis Prosedur Penerimaan Pendapatan

Daerah Melalui Bendahara Penerimaan Pada Dinas Pendapatan Pengelolaan

Keuangan dan Aset Daerah (DPPKAD) Kabupaten Kepulauan Sitaro. Jurnal EMBA.

Pontoh, W (2013). Akuntansi Konsep dan Aplikasi. Halaman Moeka Publishing. Jakarta

Robert. L. H (2013). Konsep Sistem Pengendalian Intern. Penerbit Andi. Yogyakarta Romney. R dan Steinbart. L (2006). Akuntansi Keuangan. Edisi ke-12. Erlangga: Jakarta Sunanto (2017). Analisis Efisiensi Dan Efektivitas Penerimaan Pendapatan Asli Daerah Terhadap Anggaran Pendapatan Dan Belanja Daerah (APBD) di Kabupaten Musi Banyuasin. Jurnal MONEX Vol. 6 No. 1. 